\title{
Qualitative and quantitative evaluation of residual microplastics in ark shell
}

\author{
Han-Cheol Lee, Ah-Hyeon Jo, Ju-Yeong Kang, Eun-Ji Park, \\ Min-Ji Park, Jung-Beom Kim* \\ Department of Food Science and Technology, Sunchon National University, Suncheon 57922, Korea
}

\section{피조개 중 잔류 미세플라스틱의 정성 및 정량 평가}

\author{
이한철 · 조아현 · 강주영 · 박은지 · 박민지 · 김중범*
}

순천대학교 식품공학과

\begin{abstract}
The characteristics and particle numbers of residual microplastics were investigated in ark shell to establish a food safety management method. The ark shell employed herein was purchased in Jeonnam province. The experimental method involved disassembly of the organic matter present in the ark shell using $10 \% \mathrm{KOH}$, followed by qualitative and quantitative analysis of the microplastics using Fourier transform infrared (FT-IR) spectroscopy. The mean value of residual microplastics was 0.8 microplastic (MP)/individual in ark shell $\mathrm{A}$, and were found to consist of one polypropylene (PP), two polyethylenes (PE), and one epoxy. The mean value of residual microplastics was 1.2 MP/individual in ark shell B, and were found to consist of two PP, two PE, and two polyesters. In ark shell $\mathrm{C}$, the mean value of residual microplastics was 1.6 MP/individual, consisting of two PP, two PE, two polyesters, and two acrylates. These results indicated that the residual microplastics in the ark shell are present in relatively lower quantitative levels compared to the results presented in previous reports. However, due to the ability of microplastics to contaminate marine life by absorbing harmful chemicals, thereby adversely affecting marine food product safety, regular monitoring of the residual microplastics present in marine products is necessary to ensure food safety.
\end{abstract}

Key words : ark shell, microplastic, residue, qualitative, quantitative

\section{서 론}

피조개는 고막류 중 가장 중요한 국내 생산 종으로 우리 나라 전 연안의 깊은 수심에 서식한다(Park 등, 1998). 고막 류 중 피조개는 크기가 가장 크고 육질이 연하며 맛이 좋아 남해안에서 양식되고 있다(Park 등, 1998). 과거 피조 개는 단백질 보충원으로 이용되었지만, 최근 생리활성에 대한 기능성이 보고되고 있다(Kim 등, 2014; Kang, 2017). 피조개는 전체 지방산 중 다가 불포화지방산이 $35.5 \%$ 를
차지하며(National Fisheries Research Development Institute, 2019), 글루탐산이 $205 \mathrm{mg} / 100 \mathrm{~g}$, 타우린이 $628 \mathrm{mg} / 100$ $\mathrm{g}$, 유리 아미노산이 $1,966 \mathrm{mg} / 100 \mathrm{~g}$ 함유되어 있다(Park, 2002). 피조개의 생리활성이 밝혀짐에 따라 생산량은 2006 년 2,212톤에서 2017년 4,524톤으로 약 2배 증가하였다 (Korea Rural Economic Institute, 2018). 그러나 2011년 소비 자 1,000 명에게 식품안전 인식을 조사한 결과, 육류, 채소 류, 패류 중 패류에 대한 안전성에 대해 가장 큰 우려를 나타났다(Trend Monitor, 2011). 또한, 패류는 여과섭이 활

*Corresponding author. E-mail : okjbkim@sunchon.ac.kr, Phone : +82-61-750-3259, Fax : +82-61-750-3208

Received 17 February 2020; Revised 18 March 2020; Accepted 19 March 2020.

Copyright (c) The Korean Society of Food Preservation.

This is an Open Access article distributed under the terms of the Creative Commons Attribution Non-Commercial License (http://creativecommons.org/licenses/by-nc/4.0) which permits unrestricted non-commercial use, distribution, and reproduction in any medium, provided the original work is properly cited. 
동을 통해 해수에 존재하는 중금속, 유해화학물질 등을 섭취하고 체내에 축적하여 식품안전의 위해요소로 작용 할 수 있다고 보고되고 있다(Cliver, 1988; Chen 등, 2008).

플라스틱 생산량은 전 세계적으로 꾸준히 증가하여 2012년 전 세계 플라스틱 생산량은 2억 8천 톤으로 지난 60 년 사이 170 배 증가하였다. 이러한 추세로 플라스틱 생 산량이 증가한다면 2050년에는 그 누적 량이 330 억 톤에 이를 것으로 전망되고 있다(Birol, 2018). 플라스틱 생산량 의 증가와 함께 해양으로 배출되는 플라스틱의 양 또한 증가하여 해양쓰레기 중 플라스틱 비율이 60-80\%를 차 지하고 있다(Derraik, 2002). 미국 해양대기관리처는 플라 스틱 중에서도 $5 \mathrm{~mm}$ 미만의 플라스틱을 미세플라스틱 (microplastic, MP)이라 정의하고 있다(Santos와 Duarte, 2015). 세계자연기금의 플라스틱 인체 섭취평가 연구에 따르면 한 사람이 일주일간 섭취하는 미세플라스틱의 양 은 $5 \mathrm{~g}$ 이라고 보고하고 있다(World Wide Fund for Nature, 2019).

미세플라스틱 분석방법은 유기물 분해, 비중 분리, Fourier transform infrared(FT-IR)를 이용한 분석이 가장 일 반적으로 사용되는 실험방법이다(Andrady, 2011; Lee와 Kim, 2017; Shim 등, 2017a). 시료에 포함된 유기물질 등은 미세플라스틱의 정성 및 정량 분석 시 방해물질로 작용할 수 있어 유기산을 이용하여 제거한다(Lee와 Kim, 2017). 비중 분리는 미세플라스틱과 다른 오염물질의 밀도 차이 를 이용해 미세플라스틱을 분리한다(Chae 등, 2014). FT-IR 은 적외선 영역의 빛이 시료에 입사되어 시료와 상호 작용 하는 빛의 투과율과 반사율을 측정함으로써 시료의 정성 분석이 가능한 분광법이다(Lee 등, 2016).

플라스틱은 생산과정 중 화학적, 물리적 성질을 극대화 하기 위해 bisphenol-A, phthalates, tetrabromobisphenol A 등의 화학물질을 첨가한다(Mato 등, 2001). 플라스틱의 가 소제, 안정제 등으로 사용되는 bisphenol-A, phthalates, tetrabromobisphenol A 등의 유해화학물질은 플라스틱이 분해되면 환경에 용출되어 독성물질로 작용하고 있다 (Cole 등, 2011). 또한, 작게 분해된 미세플라스틱의 공극에 중금속을 포함한 무기화학물질(Chae 등, 2014)과 유기화학 물질이 다양하게 흡착되는 것으로 보고되고 있다(Teuten 등, 2007). 크기가 2-3 mm의 polypropylene(PP) 펠릿은 잔류 유기오염물질(persistent organic pollutants, $\mathrm{POPs}$ )을 해수보다 $10^{5}$ 배 이상 흡착하고 있다(Mato 등, 2001). 잔류 유해물질에 오염된 미세플라스틱을 해양 생물이 섭취할 경우 가장 큰 피해는 먹이사슬의 최종 단계에 있는 인간이 다. 미세플라스틱 오염 예방은 해양생태계 보호뿐만 아니 라 식품안전과 직결되는 문제이다(Moore 등, 2002; Browne 등, 2008). 그러나 현재까지 미세플라스틱 오염에 대한 연 구는 매우 미약한 실정이다. 따라서 본 연구에서는 시중에
유통 중인 피조개에 대한 미세플라스틱 잔류실태를 조사하 여 식품 안전관리 방안의 기초자료로 활용하고자 하였다.

\section{재료 및 방법}

\section{재료}

본 실험에 사용된 재료는 전라남도 일부지역 시장에서 판매되는 피조개를 3 곳에서 구매하였으며, 구입된 각각의 피조개 중 5 개씩 취하여 실험에 사용하였다. 각각 5 개의 중량이 유사하도록 피조개를 선택하였다.

\section{실험방법}

\section{유기물 분해 및 체거름}

유기물 분해와 체거름은 Kim 등(2019)의 보고에 따라 실험하였다. 각각 5 마리 피조개에서 추출한 가식부를 1 $\mathrm{L}$ 비커에 넣은 후 $10 \%-\mathrm{KOH}$ (Daejung, Siheung, Korea) 용 액 $500 \mathrm{~mL}$ 를 첨가하여 약 $40^{\circ} \mathrm{C}$ 의 항온수조 $(\mathrm{WB}-20 \mathrm{M}$, Jeiotech, Daejeon, Korea)에서 2시간 간격으로 교반하며 48시간 정치시켰다. 육안으로 유기물 제거 정도를 확인한 후 $100 \mu \mathrm{m}$ 체(Test sieve, Chunggey industrial, Gunpo, Korea) 에 걸러 증류수로 세척하였다.

\section{비중 분리 및 감압 여과}

비중 분리는 $\mathrm{Kim}$ 과 $\operatorname{Kim}(2015)$ 의 방법에 따라 체에 걸러 진 입자를 $\mathrm{NaCl}$ 용액(Daejung)을 이용하여 분액깔대기에 옮긴 후 12 시간 정치시켰다. 침전된 불순물을 2 시간 간격 으로 2 번 제거하였다. 비중 분리된 시료를 공극이 $45 \mu \mathrm{m}$ 인 여과지(Mesh filter, Taemyong Science, Uiwang, Korea)로 감압 여과한 뒤, 여과지를 유리제 petridish 담아 실온에서 건조시켰다.

\section{$\mathrm{FT}-\mathrm{IR}$ 분석}

건조한 여과지를 Andrady(2011)의 방법에 따라 FT-IR (iN10 MX, Thermo Fisher, Waltham, MA, USA)을 이용하 여 분석하였다. 여과지를 시료 분석구에 장착한 후, 분석 면적을 미세하게 구획하였다. 각각의 구획에서 발견된 particle 수를 정량분석의 결과로 활용하였으며, particle의 스펙트럼을 분석한 후 library 검색을 통해 재질을 판별하 였다. Library 검색결과, hit quality $>700$ 이상인 경우 동일 한 재질로 판정하였다(Chae 등, 2015).

\section{결과 및 고찰}

각각 피조개의 미세플라스틱 잔류량은 Table 1에 나타 
Table 1. Quantitative evaluation of residual microplastics in ark shell

\begin{tabular}{ccccc}
\hline Type $^{1)}$ & Total weight $(\mathrm{g})$ & Edible weight $(\mathrm{g})$ & No. of total microplastic & $\begin{array}{c}\text { Mean } \\
(\text { MP/Individual) }\end{array}$ \\
\hline Ark shell A & $68.9 \pm 3.9$ & $33.0 \pm 3.2$ & 4 & 0.8 \\
Ark shell B & $70.8 \pm 5.3$ & $32.0 \pm 2.7$ & 6 & 1.2 \\
Ark shell C & $69.0 \pm 4.6$ & $31.1 \pm 4.0$ & 8 & 1.6 \\
\hline Total & $69.6 \pm 4.4$ & $32.1 \pm 3.2$ & 18 & $1.2 \pm 0.4$ \\
\hline
\end{tabular}

${ }^{1)}$ Ark shell A-C, ark shell purchased place.

내었고, 재질별 microplastic의 사진과 스펙트럼은 Figs. 1 - 2에 나타내었다. 피조개 $\mathrm{A}$ 의 가식부는 $33.0 \pm 3.2 \mathrm{~g}$ 으로 총 4 개의 미세플라스틱이 검출되어, 한 개 피조개 당 0.8 $\mathrm{MP} / \mathrm{Individual}$ 로 나타났고, 재질은 PP 1개, PE 2개, epoxy 1 개로 분석되었다. 피조개 $\mathrm{B}$ 의 가식부는 $32.0 \pm 2.7 \mathrm{~g}$ 으로 총 6 개의 미세플라스틱이 검출되어, 한 개 피조개 당 1.2 MP/Individual로 나타났고, 재질은 PP 2개, PE 2개, polyester 2개로 분석되었다. 피조개 $\mathrm{C}$ 의 가식부는 $31.1 \pm 4.0 \mathrm{~g}$ 으로 총 8 개의 미세플라스틱이 검출되어, 한 개 피조개 당 1.6 MP/Individual로 나타났고, 재질은 PP 1개, PE 3개, polyester 2개, acrylate 2 개로 분석되었다.

본 실험에서 사용한 FT-IR 분석법은 가장 일반적인 미 세플라스틱 분석방법으로 Nile red 염색법(Kim 등, 2018), Raman spectroscopy(Ryu와 Cho, 2019) 등 타 실험법과 비 교 시 플라스틱 유사 입자에 대한 확인이 가능하여 오탐지 가능성이 없는 비파괴 분석법이다(Shim 등, 2017b). 본 실
험에 사용된 피조개의 미세플라스틱 잔류량의 평균은 $1.2 \pm 0.4 \mathrm{MP} /$ Individual로 나타났다. 본 실험 결과와 캐나다 Baynes Sound에서 채취한 바지락에서 미세플라스틱 잔류량 이 평균 $8.4 \pm 8.5 \mathrm{MP} /$ Individual로 나타났다는 보고(Davidson 과 Dudas, 2016)와 중국 남부에서 채취한 굴의 미세플라스 틱 잔류량이 최대 $9.08 \pm 5.70 \mathrm{MP} /$ Individual로 검출되었다 는 보고(Teng 등, 2019)와 비교 시 상대적으로 낮은 잔류량 을 나타내었다. 본 실험결과, 시중 유통 중인 피조개의 미세플라스틱 오염도는 낮은 것으로 판단되나 미세플라 스틱은 유해화학물질을 흡착하여 해양 생물을 오염시키 고 먹이사슬의 최종 단계인 인간에게까지 악영향을 미칠 수 있다. 또한, 초미세플라스틱을 섭취하면 세포 소기관인 미토콘드리아까지 침투하여 세포 활성을 저하시키고, 다 른 물질에 의한 독성을 증폭시키는 역할을 할 수 있다고 보고되고 있다(Lee 등, 2019). 실험결과, 모든 시료에서 PP 와 $\mathrm{PE}$ 가 검출되었는데, 이는 플라스틱 종류 중 가장 밀도

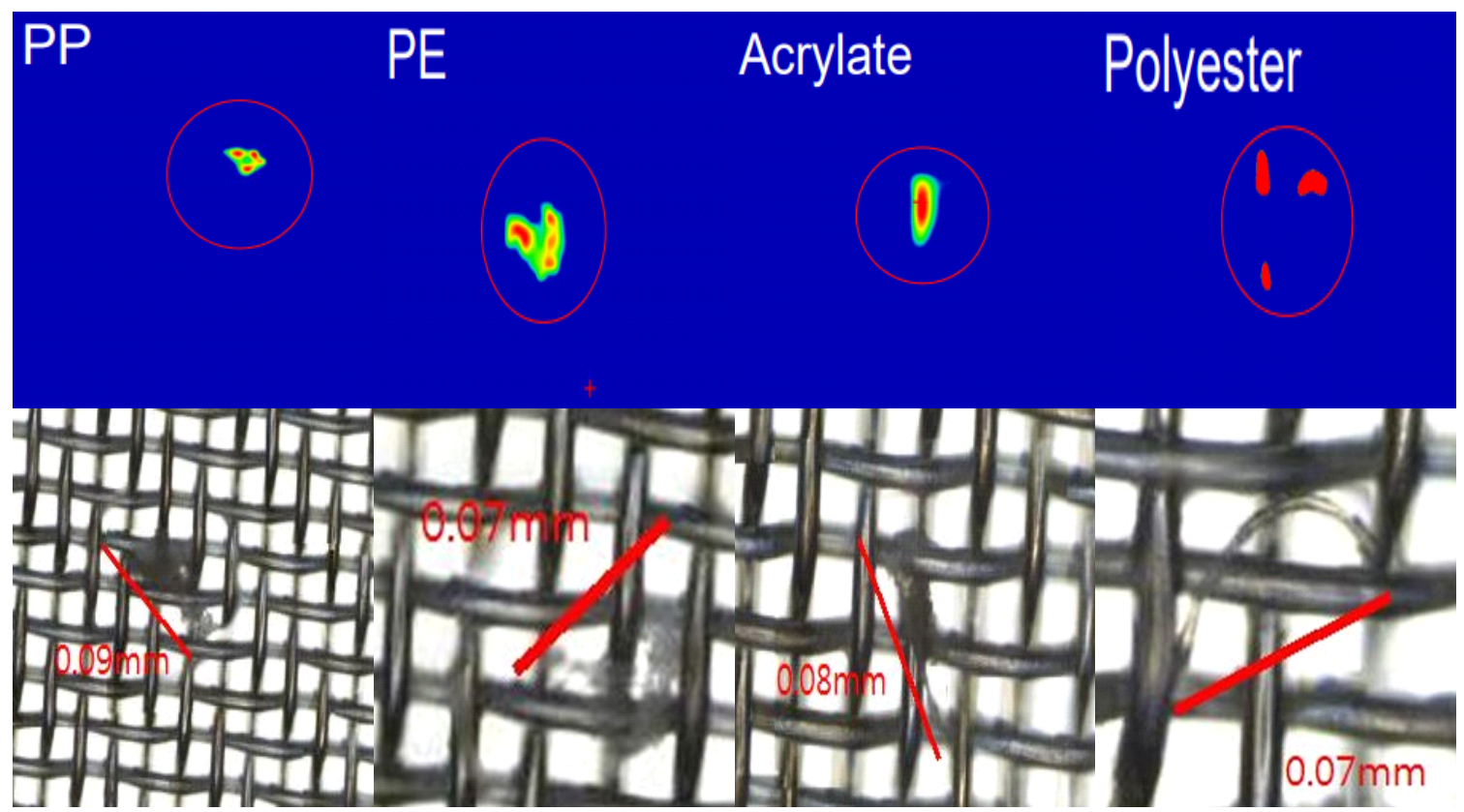

Fig. 1. Photograph of microplastic in ark shell. 

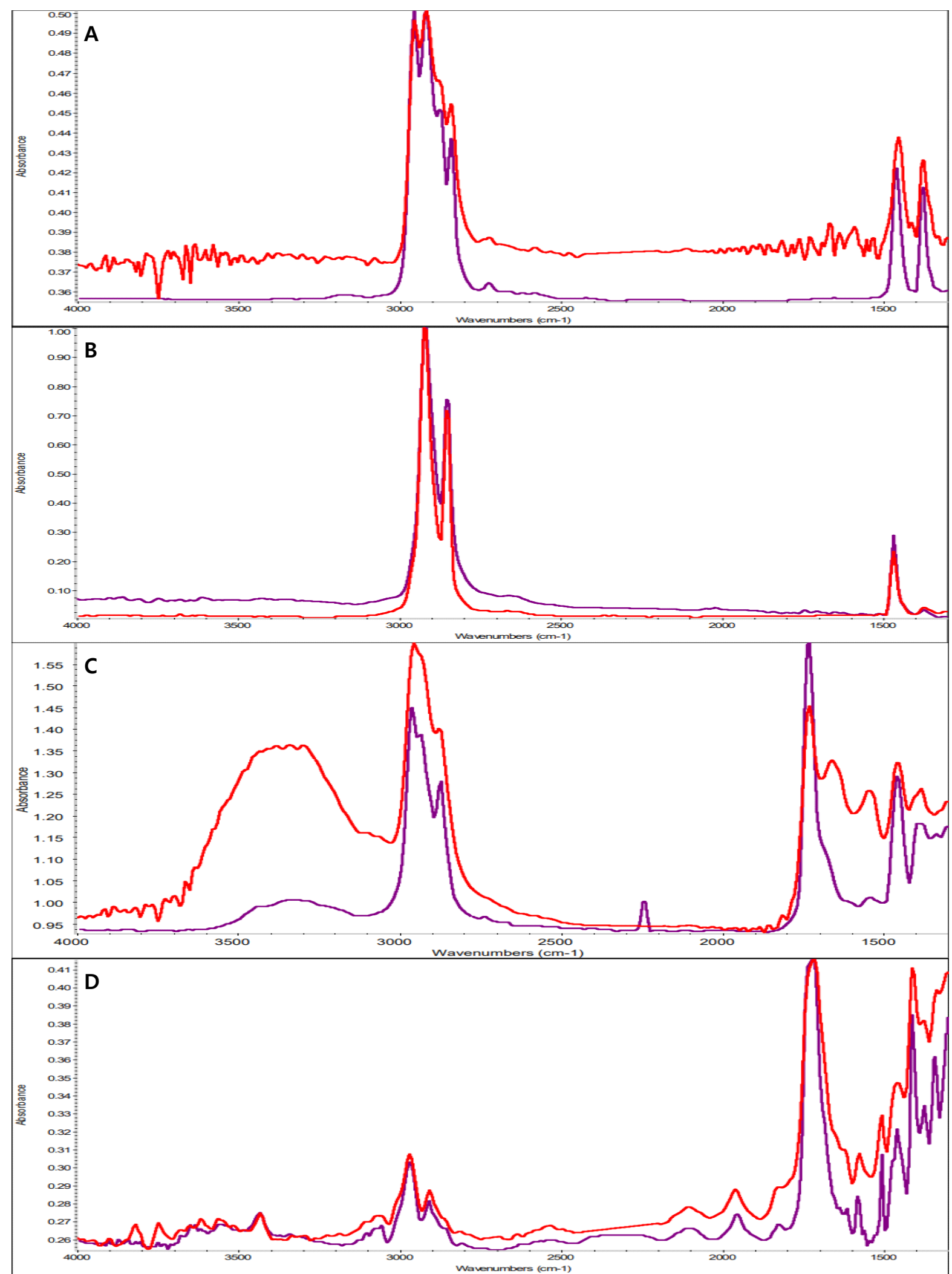

Fig. 2. Comparison of sample (red) and library (purple) in FT-IR spectrum. A, PP; B, PE; C, acrylate; D, polyester. 
가 낮아(Lee와 Kim, 2017) 비중 분리 과정에서 손실이 적 고, 수심이 낮은 갯벌에서 피조개를 양식(Kim 등, 2007)하 기 때문에 $\mathrm{PP}$ 와 $\mathrm{PE}$ 의 검출률이 높은 것으로 판단된다. 따라서 시중 유통 중인 수산물의 미세플라스틱 잔류량을 주기적으로 모니터링하여 수산물에 의한 미세플라스틱 섭취를 저감화하여야 할 것으로 판단된다.

\section{요 약}

본 연구에서는 유통 중인 피조개에 대한 미세플라스틱 잔류실태를 조사하여 식품 안전관리 방안의 기초자료로 활용하고자 하였다. 본 실험에 사용된 재료는 전라남도 일 부 지역 시장에서 판매되는 피조개를 대상으로 하였다. 피 조개 가식부를 $10 \% \mathrm{KOH}$ 로 분해한 후 Fourier transform infrared를 이용하여 분석하였다. 피조개 $\mathrm{A}$ 의 미세플라스틱 잔류량은 $0.8 \mathrm{MP} /$ Individual, 재질은 $\mathrm{PP}, \mathrm{PE}$, epoxy로 분석되 었다. 피조개 $\mathrm{B}$ 의 미세플라스틱 잔류량은 $1.2 \mathrm{MP} /$ Individual, 재질은 $\mathrm{PP}, \mathrm{PE}$, polyester로 분석되었다. 피조개 $\mathrm{C}$ 의 미세 플라스틱 잔류량은 $1.6 \mathrm{MP} /$ Individual, 재질은 $\mathrm{PP}, \mathrm{PE}$, polyester, acrylate로 분석되었다. 미세플라스틱은 유해화 학물질을 흡착하여 해양 생물을 오염시키고, 수산물 안전 에 악영향을 미칠 수 있어 수산물에 대한 미세플라스틱 잔류량을 주기적으로 모니터링하여야 할 것으로 판단되 었다.

\section{Conflict of interests}

The authors declare no potential conflict of interest.

\section{ORCID}

Han-Cheol Lee https://orcid.org/0000-0002-1772-3964 Jung-Beom Kim https://orcid.org/0000-0002-0290-2687

\section{References}

Andrady AL. Microplastics in the marine environment. Mar Pollu Bull, 62, 1596-1605 (2011)

Browne MA, Dissanayake A, Galloway TS, Lowe DM, Thompson RC. Ingested microscopic plastic translocates to the circulatory system of the mussel, Mytilus edulis (L.). Environ Sci Technol, 42, 5026-5031 (2008)

Birol F. The future of petrochemicals towards more sustainable plastics and fertilisers. IEA, International Energy Agency, 1-18 (2018)

Cliver DO. Virus transmission via foods. Food Technol, 42,
241-248 (1988)

Chen CY, Serrell N, Evers DC, Fleishman BJ, Lambert KF, Weiss J, Mason RP, Bank MS. Meeting report: Methylmercury in marine ecosystems from sources to seafood consumers. Environ Health Perspect, 116, 1706-1712 (2008)

Cole M, Lindeque P, Halsband C, Galloway TS. Microplastics as contaminants in the marine environment: A review. Mar Pollut Bull, 62, 2588-2597 (2011)

Chae DH, Kim IS, Song YK, Kim SW, Kim SK. Development of analytical method for microplastics in seawater. J Korean Soc Oceanography, 19, 88-98 (2014)

Chae DH, Kim IS, Kim SK, Song YK, Shim WJ. Abundance and distribution characteristics of microplastics in surface seawaters of the Incheon/Kyeoinggi coastal region. Arch Environ Contam Toxicol, 69, 269-278 (2015)

Derraik JGB. The pollution of the marine environment by plastic debris: A review. Mar Pollut Bull, 44, 842-852 (2002)

Davidson K, Dudas SE. Microplastic ingestion by wild and cultured Manila clams (Venerupis philippinarum) from Baynes Sound, British Columbia. Arch Environ Contam Toxicol, 71, 147-156 (2016)

Kim JB, Lee SY, Jung CG, Jung CS, Son SG. The effects of the spat planting time and environmental factors in the arkshell, Scapharca broughtonii Schrenck culture. J of Aquaculture, 20, 31-40 (2007)

Kim JB, Kim JM, Lee YM, Baek IS, Lee SC. Antioxidant activity and acetylcholinesterase inhibitory activity of ark shell (Scapharca broughtonii). Korean J Food Cook Sci, 30, 212-218 (2014)

Kim IS, Kim SK. Seasonal distribution characteristics of microplastics in the sand beach of the Daebu Island, Gyeonggi-do. J Korean Soc Environ Eng, 18, 221-231 (2015)

Kim EG, Kim JH, Kim JH, Park SI, Lee EJ. Microplastic analysis method in drinking water using staining method and FT-IR compare. J Korean Soc Environ Eng, 27, 154-154 (2018)

Kang GT. Development of a HACCP system model for oyster Crassostrea gigas processing workplace. Ph D Thesis, Gyeongsang National University, Korea, p 1-5 (2017)

Korea Rural Economic Institute. 2017 Food Balance Sheet. Seoul, Korea, p 244-256 (2018)

Kim NS, Yoon JD, Lee SE, Park YJ, Woo SH. A study on the residual microplastics in freshwater and fishes in 
the Geum River watershed. KJEE, 52, 28-39 (2019)

Lee JH, Park CH, Huh IA, Shin KS, Lee SH, Lee YS, Lee

SY, Lee SH. Studies on the Investigation Method of Microplastic in the Freshwater. Final Report of ME, 1485014370 (2016)

Lee HS, Kim YJ. Consideration on quantitative and qualitative analysis for microplastic in various madia. $\mathrm{J}$ Korea Soc Waste Manage, 34, 537-545 (2017)

Lee WS, Cho HJ, Kim EW, Huh YH, Kim HJ, Kim BS, Kang TJ, Lee JS, Jeong JY. Bioaccumulation of polystyrene nanoplastics and their effect on the toxicity of $\mathrm{Au}$ ions in zebrafish embryos. Nanoscale, 11, 31733185 (2019)

Mato Y, Isobe T, Takada H, Kanehiro H, Ohtake C, Kaminuma T. Plastic resin pellets as a transport medium for toxic chemicals in the marine environment. Emviron Sci Technol, 35, 318-324 (2001)

Moore MR, Vetter W, Gaus C, Shaw GR, Muller JF. Trace organic conpounds in the marine environment. Mar Pollut Bull, 45, 62-68 (2002)

National Fisheries Research Development Institute. Nutrient Database for Ark shell. https://www.nifs.go.kr/page?id= aq_seafood_2_7\&type=tot\&from=totList\&fim_col_id= 2018-MF0004224-6-D01. (accessed Jan 2020)

Park MS, Lim HJ, Kim PJ. Effect of environmental factors on the growth, glycogen and hemoglobin content of cultured arkshell, Scapharca broughtonii. J Korean Fish Soc, 31, 176-185 (1998)

Park CK. Comparison of extractive nitrogenous constituents in the three species of raw bloody clams, Scaphrca broughtonii, S. subcrenata, and Tegellarca granosa extracts. Korean J Food Sci Technol, 34, 954-961 (2002)

Ryu JH, Cho CY. Current status of microplastics and impact on human health. J Ind Eng Chem, 22, 1-12 (2019)

Santos TR, Duarte AC. A critical overview of the analytical approaches to the occurrence, the fate and behavior of microplastics in the environment. TrAC-Trends Anal Chem, 65, 47-53 (2015)

Shim WJ, Hong SH, Cho YN, Han GM, Song YK, Jang M, Eo SE, Hong L, Yi ALJ. Research on Food Safety Management for Microplastics. Final Report of MFDS, 1475010028 (2017a)

Shim WJ, Hong SH, Eo SE. Identification methods in microplastic analysis: A review. Anal Methods, 9, 13841397 (2017b)

Teuten EL, Rowland SJ, Galloway TS, Thompson RC. Potential for plastics to transport hydrophobic contaminants. Emviron Sci Technol, 41, 7759-7764 (2007)

Trend Monitor. Consumers Perception of Food Safety. https:// www.trendmonitor.co.kr/tmweb/trend/allTrend/detail.do? bIdx $=777 \&$ code $=0404 \&$ trendType $=$ CKOREA $\quad$ (accessed Jan 2020)

Teng J, Wang Q, Ran W, Wu D, Liu Y, Sun S, Liu H, Cao R, Zhao J. Microplastic in cultured oysters from different coastal areas of China. Sci Total Environ, 653, 1282-1292 (2019)

World Wide Fund for Nature. https://wwf.panda.org/wwf news/press_releases/?348337/Revealed-plastic-ingesti on-by-people-could-be-equating-to-a-credit-card-a-week. (accessed Jan 2020) 